\title{
KAJIAN KESELAMATAN PENGOPERASIAN REAKTOR TRIGA 2000 BANDUNG DENGAN MENGGUNAKAN BATANG KENDALI REAKTOR TRIGA 2000 TANPA BAHAN BAKAR (BKRTTBB)
}

\author{
Prasetyo Basuki ${ }^{1}$, A.R. Iso Suwarso ${ }^{1}$, Agus Sunarya ${ }^{1}$, P. Ilham Yazid ${ }^{1}$, \\ Supardjo ${ }^{2}$, Abdul Rojak ${ }^{2}$ \\ ${ }^{1}$ Pusat Sains dan Teknologi Nuklir Terapan - Bandung \\ ${ }^{2}$ Pusat Teknologi Bahan Bakar Nuklir - Serpong \\ Diterima: 16-06-2015 \\ Diterima dalam bentuk revisi: 30-06-2015 \\ Disetujui: 08-07-2015
}

\begin{abstract}
ABSTRAK
KAJIAN KESELAMATAN PENGOPERASIAN REAKTOR TRIGA 2000 BANDUNG DENGAN MENGGUNAKAN BATANG KENDALI REAKTOR TRIGA 2000 TANPA BAHAN BAKAR (BKRTTBB). Telah dilakukan kegiatan pabrikasi BKRTTBB untuk digunakan pada teras TRIGA 2000 Bandung sebagai upaya modifikasi batang kendali pengganti FFCR (Fuel Follower Control Rod) yang telah memiliki fraksi bakar melebihi $50 \%$ pada bagian elemen pengikutnya. Dari 5 buah FFCR yang digunakan saat ini telah terindikasi 2 buah yang memiliki fraksi bakar melebihi $50 \%$ dan 1 buah yang telah mendekati $50 \%$. Sampai dengan akhir tahun ini direncanakan dilakukan penggantian sebanyak 2 buah, dan akan berlanjut sampai dengan 4 buah di tahun berikutnya. Untuk dapat menjamin keselamatan proses modifikasi dan pasca modifikasi, maka perlu dilakukan kajian simulasi operasi dengan menggunakan BKRTTBB pada skenario teras paling reaktif. Pada kajian ini telah dilakukan simulasi operasi dengan menggunakan 1 buah FFCR, 4 buah BKRTTBB, dan 102 elemen bakar dengan komposisi elemen bakar sesuai dengan kondisi terkini pada teras TRIGA 2000 dengan menggunakan MCNP. Dari kajian ini didapatkan beberapa parameter kritikalitas antara lain reaktivitas teras lebih (core excess) sebesar $\$ 5,461$, dan reaktivitas padam (shutdown margin) sebesar $\$-9,647$, kemudian dengan menskenariokan kondisi one stuck rod didapatkan bahwa semua kondisi salah satu batang kendali tersangkut memberikan respons subkritis. Kemudian dari simulasi ini pula didapatkan faktor puncak daya aksial sebesar 1,21 dan faktor puncak daya radial sebesar 2,02. Dari kedua nilai faktor puncak daya ini dapat dihitung distribusi suhu pada teras dengan menggunakan program komputasi STAT dan STATMOD. Hasil simulasi menggunakan STAT dan STATMOD dengan memberikan suhu masukan air sampai dengan $42{ }^{\circ} \mathrm{C}$ didapatkan suhu terpanas pada subbuluh sebesar $87,98^{\circ} \mathrm{C}$ dan $82,75^{\circ} \mathrm{C}$. Berdasarkan hasil ini dapat disimpulkan bahwa pengoperasian reaktor dengan menggunakan BKRTTBB pada kondisi yang mendekati dimana suhu air masukan mendekati $49{ }^{\circ} \mathrm{C}$ (suhu tertinggi untuk sinyal SCRAM), air pendingin primer belum mencapai suhu pendidihan $\left(112^{\circ} \mathrm{C}\right)$. Sehingga pengoperasian reaktor dengan BKRTTBB dapat dinyatakan aman dan selamat dari aspek neutronik maupun termalhidrolik.
\end{abstract}

Kata kunci : BKRTTBB, reaktivitas teras lebih, reaktivitas padam, faktor puncak daya, suhu.

\section{ABSTRACT}

SAFETY REVIEW OF BANDUNG TRIGA 2000 RESEARCH REACTOR OPERATION USING CONTROL ROD WITHOUT FUEL FOLLOWER (BKRTTBB). BKRTTBB manufacturing activities have been carried out to be used on the TRIGA 2000 core as a modification of the control rod replacement FFCR (Fuel Follower Control Rod) which has had burnup exceeds 50 $\%$ on the fuel follower. Two units of existing FFCR have been indicated exceeds $50 \%$ of burnup and 1 unit was approaching $50 \%$. Until the end of this year planned replacement by 2 units, and will continue up to 4 units in the next year. To ensure the safety of the modification process and the post-modification activities, it is necessary to study the operation simulation using BKRTTBB on the most reactive core. This study has been carried out on simulated reactor operation using 
1 unit FFCR, 4 units BKRTTBB, and 102 fuel elements with composition in accordance with current conditions on the TRIGA 2000 core by using MCNP. This study obtained some criticality parameters, core excess $\$ 5.461$, and shutdown margin $\$-9.647$, then the scenario of one stuck rod conditions showed that all the conditions of one control rod stuck is responded as subcritical. Then from this simulation also obtained axial peak power factor of 1.21 and radial peak power factor of 2.02. Based on these values, the temperature distribution on the reactor can be calculated using computational codes, STAT and STATMOD. The simulation results using STAT and STATMOD by providing input water temperature up to $42{ }^{\circ} \mathrm{C}$ at the hottest sub channel temperature obtained of $87.98{ }^{\circ} \mathrm{C}$ and $82.75{ }^{\circ} \mathrm{C}$. Based on these results it can be concluded that operation of the reactor by using BKRTTBB in conditions near to LOFA where no temperature exchange so that the water temperature input approaching $49{ }^{\circ} \mathrm{C}$ (the highest temperature for the scram signal), water primary coolant still has not reached the temperature of boiling $\left(112{ }^{\circ} \mathrm{C}\right)$. So that the operation of the reactor with BKRTTBB can be declared safely and secure in neutronics and termalhydraulics aspect.

Keywords: BKRTTBB, core excess, shutdown margin, power peaking factor, temperature.

\section{PENDAhULUAN}

Pada usia guna yang mencapai 50 tahun, reaktor TRIGA 2000 menghadapi per-masalahan dimana ketersediaan komponen mulai sukar untuk didapatkan bahkan dari produsennya langsung yaitu General Atomic. Permasalahan yang sangat mengemuka pada saat ini adalah kondisi faksi bakar pada 2 buah batang kendali FFCR (Fuel Follower Control Rod) yang sudah melebihi $50 \%$, dan 1 buah yang sudah mendekati $50 \%$. Sesuai dengan peraturan yang berlaku bahwa ketika burn up suatu elemen bakar telah mencapai $50 \%$, maka perlu di-lakukan penggantian dengan yang masih baru.

Dengan tidak adanya pasokan dari General Atomic maka BATAN berinisiatif untuk membuat batang kendali pengganti. PTBBN (Pusat Teknologi Bahan Bakar Nuklir) ditunjuk sebagai satker yang bertanggungjawab dalam melakukan riset dan pabrikasi batang kendali pengganti tersebut.

Adapun batang kendali pengganti yang dibuat oleh PTBBN adalah batang kendali tanpa elemen bakar pengikut (fuel follower). Namun batang kendali dibuat sepenuhnya mengacu pada desain FFCR TRIGA 2000. Bahan kelongsong, bahan penyerap neutron sepenuhnya sama dan dimensinya pun sama. Batang kendali pengganti modifikasi ini selanjutnya diberi nama Batang Kendali Reaktor TRIGA 2000 Tanpa Bahan Bakar (BKRTTBB). Perbandingan antara FFCR dan BKRTTBB dapat dilihat pada Gambar 1. Adapun spesifikasi BKRTTBB apabila dibanding-kan dengan FFCR adalah sebagai berikut:

i. Material dan dimensi kelongsong BKRTTBB dibuat sesuai spesifikasi FFCR (1).

ii. Material penyerap neutron pada FFCR menggunakan $\mathrm{B}_{4} \mathrm{C} \varnothing 3,36 \mathrm{~cm}$ sepanjang $38,1 \mathrm{~cm}$ (15"), sedangkan BKRTTBB menggunakan $\mathrm{B}_{4} \mathrm{C} \varnothing 3,36$ cm sepanjang $8 \times 5 \mathrm{~cm}(15,75 ")$ (1).

iii. Bahan bakar FFCR diganti rod SS-304 dengan berat yang sama (1).

iv. Penggabungan tutup atas dan tutup bawah dengan kelongsong menggunakan las TIG, sedangkan pada FFCR menggunakan las Pulsed 
Magnetic Welding (1).

v. Metode Crimping dilakukan untuk mengurangi beban las terhadap berat BKRTTBB dan membantu stabilitas posisi masing-masing komponen (1).

vi. Stabilisasi komponen ring penjarak dan piring penyangga terhadap kelongsong FFCR mengunakan metode magneform, sedangkan pada BKRTTBB menggunakan metode crimping (1).

vii. Penyumbatan lubang pengisian gas $\mathrm{He}$ pada FFCR menggunakan metode keling dan las TIG, sedangkan pada BKRTTBB menggunakan sekrup dan las TIG (1).

Tujuan penelitian ini adalah untuk dapat menjamin bahwa BKRTTBB dapat dioperasikan dengan aman dan selamat maka perlu dilakukan suatu kajian keselamatan. Kajian keselamatan BKRTTBB adalah kajian kritikalitas penggunaan BKRTTBB pada teras TRIGA 2000 saat ini, dan kajian perpindahan kalor pada teras untuk mengamati karakteristik termalhidrolikanya apabila reaktor dioperasikan pada daya maksimum sampai dengan 1000 $\mathrm{kW}$.

Kajian keselamatan kritikalitas dilakukan menggunakan MCNP dengan mensimulasikan penggunaan BKRTTBB pada teras TRIGA 2000 kondisi paling reaktif. Kondisi teras reaktif adalah kondisi dimana reaktivitas teras memiliki nilai yang cukup besar dengan mangacu pada komposisi elemen bakar yang digunaka saat ini, dengan cara mengoptimalkan konfigurasi heksagonal yang ada pada teras. Kemudian kaji teoritis dan eksperimental aspek termohidrolik reaktor TRIGA 2000 pada berbagai daya reaktor telah dibahas secara rinci dalam beberapa literatur (2-7). Demikian pula analisis untuk beberapa kegiatan modifikasi juga sudah dilakukan $(8,9)$ dalam rangka mendapatkan kodisi yang memenuhi semua persyaratan keselamatan yang sudah ditetapkan.

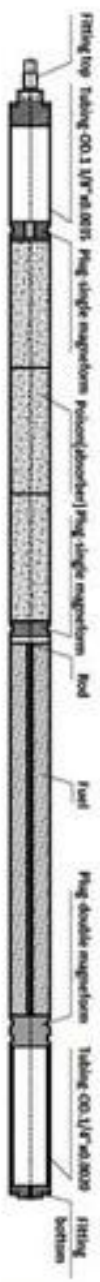

(a)

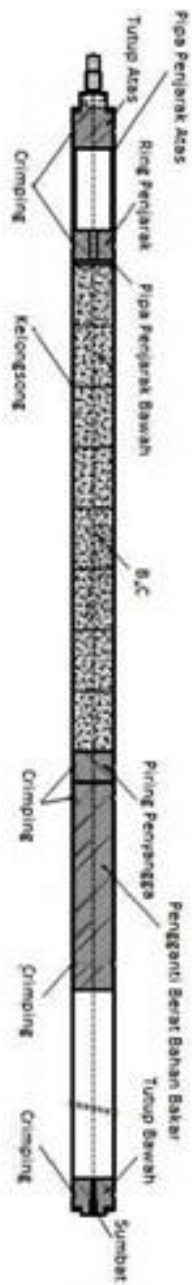

(b)
Gambar 1. Perbandingan kedua batang kendali: (a) FFCR; (b) BKRTTBB

Pada kegiatan modifikasi batang kendali dengan BKRTTBB ini, kajian keselamatan termalhidrolik dilakukan dengan memperkirakan suhu terpanas pada 
subbuluh menggunakan STAT dan STATMOD. STAT merupakan program komputasi kaji teoritis termalhidrolik untuk reaktor berjenis TRIGA (10). Sedangkan STATMOD merupakan program komputasi STAT yang telah dimodifikasi agar sesuai reaktor TRIGA 2000 (4). Sebagai masukan digunakan faktor puncak daya hasil perhitungan dengan MCNP, dan beberapa parameter operasi lainnya yang mengacu pada skenario konfigurasi teras reaktif yang telah disimulasikan oleh MCNP.

\section{TEORI}

Reaktivitas teras lebih adalah reaktivitas yang tersedia dalam reaktor ketika batang kendali naik (berada pada posisi maksimum) (11), sedangkan reaktivitas padam adalah reaktivitas yang dimiliki reaktor ketika semua batang kendali berada pada posisi didalam teras (11). Salah satu persyaratan keselamatan neutronik reaktor nuklir adalah rentang reaktivitas yang harus cukup baik dari posisi padam sampai dengan posisi daya maksimum, dimana didefinisikan sebagai selisih antara reaktivitas teras lebih dan reaktivitas padam dan biasa disebut sebagai control rod worth (11).

$$
\rho=\frac{k_{e f f}-1}{k_{e f f}}
$$

dengan,

$\rho \quad$ : reaktivitas

$\mathrm{k}_{\text {eff }} \quad$ : faktor multiplikasi

Adapun control rod worth dirumuskan sebagai berikut:

$$
\rho_{C r}=\rho_{c e}-\rho_{s m}
$$

dengan,

$$
\begin{array}{ll}
\rho_{C r} & =\text { control rod worth } \\
\rho_{c e} & =\text { reaktivitas teras lebih } \\
\rho_{s m} & =\text { reaktivitas padam }
\end{array}
$$

Kemudian persyaratan lainnya yang harus dipenuhi adalah pemenuhan kondisi aman apabila salah satu batang kendali dengan reaktivitas terbesar gagal jatuh (one stuck rod criteria) dimana respons reaktivitas masih menunjukkan kondisi subkritis. Kondisi subkritis yang dimaksud adalah tidak melebihi \$ $-0,5$.

Selain kriteria neutronik, kondisi aman dan selamat harus pula memperhatikan sudut pandang termalhidrolika atau perpindahan kalornya. Kegiatan operasi reaktor TRIGA 2000 dengan menggunakan BKRTTBB ke depan akan dioperasikan pada daya maksimum $1000 \mathrm{~kW}$. Untuk itu kajian keselamatan termalhidrolika harus mengedepankan kondisi selamat operasi pada daya $1000 \mathrm{~kW}$, yaitu kondisi dimana air pendingin primer masih dapat memindahkan kalor dengan optimal tanpa mengalami pendidihan pada daerah subbuluh terpanas pada teras. Pada kajian termalhidrolik dengan menggunakan STAT dan STATMOD diperlukan parameter khusus yaitu faktor puncak daya. Faktor puncak daya dapat dihitung dengan menggunakan persamaan berikut:

$$
f_{\text {radial }}=\frac{p_{\max }}{p_{\text {rerata }}}
$$

dengan,

$f_{\text {radial }}=$ faktor puncak daya radial

$p_{\max }=$ rapat daya maksimum (diperoleh dari posisi elemen bakar 


$$
\begin{gathered}
p_{\text {rerata }}=\begin{array}{l}
\text { terpanas) } \\
\text { rapat daya rata-rata untuk semua } \\
\text { elemen bakar. }
\end{array} \\
f_{\text {aksial }}=\frac{p_{\max _{i}}}{\sum_{i}^{n} p_{i}+p_{i+1} \ldots+p_{n}} \\
n
\end{gathered}
$$

dengan,

$$
\begin{aligned}
f_{\text {aksial }}= & \text { faktor puncak daya aksial } \\
p_{\text {max }_{i}=}= & \text { rapat daya maksimum pada } \\
& \text { segmen ke-i dari elemen bakar }
\end{aligned}
$$

$$
\frac{\sum_{i}^{n} p_{i}+p_{i+1} \ldots+p_{n}}{n}=\text { rapat daya rata-rata }
$$

pada suatu elemen bakar yang terbagi menjadi $\mathrm{n}$ buah segmen $(11,12)$.

\section{TATA KERJA}

Pada kegiatan kajian ini dimodelkan suatu kondisi teras optimal dengan tetap berpegang pada kondisi fraksi bakar elemen bakar yang digunakan terkini. Adapun rencana penggantian FFCR pada operasi reaktor di masa depan adalah sebanyak 4 buah, dimana hanya shim 5 saja yang tidak diganti yaitu pada posisi ring D13, karena masih tergolong baru. Dengan ketentuan tersebut diatas diperoleh konfigurasi teras seperti pada Gambar 2. Dari Gambar 2. ditunjukkan bahwa semua BKRTTBB diberi warna biru, dan shim 5 pada posisi D13 diberi warna kuning adalah FFCR.

Berdasarkan pada ketentuan tersebut diatas didapatkanlah komposisi konfigurasi teras optimal yang berisi 1 buah FFCR, 4 buah BKRTTBB, dan 102 elemen bakar standar. Konfigurasi ini selanjutnya di- simulasikan dengan menggunakan MCNP untuk ditentukan nilai reaktivitas teras lebih dan reaktivitas padamnya. Serta simulasi kondisi salah satu batang kendali tersangkut. Untuk mengetahui pemenuhan persyaratan subkritis.

Reaktivitas teras lebih dapat diketahui dengan mensimulasikan kondisi operasi dimana semua batang kendali berada pada posisi maksimum (dinaikkan seluruhnya). Reaktivitas dihitung dari nilai $k_{\text {eff }}$ yang didapatkan dari hasil simulasi dengan menggunakan persamaan (1). Kemudian untuk reaktivitas padam dapat diketahui dengan mensimulasikan kondisi operasi dimana semua batang kendali berada pada posisi minimum (posisi dibawah sejajar teras). Reaktivitas dihitung dari nilai $\mathrm{k}_{\text {eff }}$ yang didapatkan dari hasil simulasi dengan menggunakan persamaan (1).

Kemudian untuk mengetahui pemenuhan kondisi subkritis pada saat terdapat salah satu batang kendali yang tersangkut, simulasi dilakukan dengan mengoperasikan reaktor dimana salah satu batang kendali berada pada posisi maksimum sedangkan yang lainnya barada pada posisi minimum. Simulasi ini dilakukan secara bergantian pada setiap batang kendali sebanyak lima kali, untuk mengetahui respons reaktivitas teras yang diakibatkan oleh masing-masing batang kendali yang tersangkut.

Adapun simulasi termalhidrolik dilakukan dengan menggunakan STAT dan STATMOD. Parameter yang diperlukan pada simulasi ini antara lain, diameter fuel elemen, daya reaktor, jumlah elemen bakar, 
suhu, pendekatan bentuk subbuluh (segitiga, segiempat, segienam, dan lain-lain), dan faktor puncak daya aksial dan radial. Pada simulasi ini pendekatan bentuk subbuluh dengan menggunakan bentuk segitiga. Kemudian untuk faktor puncak daya aksial didapatkan dari perhitungan tally $\mathrm{F} 7$ hasil keluaran MCNP dengan menggunakan persamaan (4) pada setiap elemen bakar yang terbagi menjadi 15 segmen. Faktor puncak daya radial dihitung dengan Persamaan (3) yaitu jumlah tally F7 setiap elemen bakar dibandingkan dengan tally F7 rata-rata elemen bakar.

Simulasi dengan menggunakan STAT dan STATMOD dilakukan dengan memodelkan operasi pada variasi daya $250 \mathrm{~kW}, 500$ kW, 750 kW, dan 1000 kW. Kemudian disetiap tingkatan daya tersebut divariasikan pula suhu air masukan mulai dari $32{ }^{\circ} \mathrm{C}, 34$ ${ }^{\circ} \mathrm{C}, 36{ }^{\circ} \mathrm{C}, 38^{\circ} \mathrm{C}, 40{ }^{\circ} \mathrm{C}, 42{ }^{\circ} \mathrm{C}$. Kemudian simulasi operasi pada kondisi khusus $49^{\circ} \mathrm{C}$ yaitu suhu maksimum dimana sinyal SCRAM akan bekerja. Tujuan dari simulasi ini adalah untuk mengetahui karakteristik suhu terpanas dari daerah subbuluh apakah mengalami pen-didihan atau tidak sampai dengan kondisi operasi $1000 \mathrm{~kW}$ pada suhu $49^{\circ} \mathrm{C}$.

\section{HASIL DAN PEMBAHASAN}

Hasil pengkajian dengan menggunakan MCNP dalam menentukan karakteristik reaktivitasnya ditunjukkan oleh grafik pada Gambar 3. Berdasarkan hasil perhitungan dengan MCNP didapatkan bahwa $\mathrm{k}_{\mathrm{eff}}$ kondisi pada saat seluruh batang kendali dinaikkan adalah 1,04093 atau apabila dihitung lebih lanjut kedalam besaran reaktivitas didapatkan nilai 0,0393 $\mathrm{dk} / \mathrm{k}$, kemudian dengan mengkonversikan kedalam satuan (\$) dengan acuan $\beta=$ 0,0072 (faktor $\beta$ untuk tipe TRIGA) didapatkan nilai reaktivitas teras lebih sebesar $\$ 5,463$.

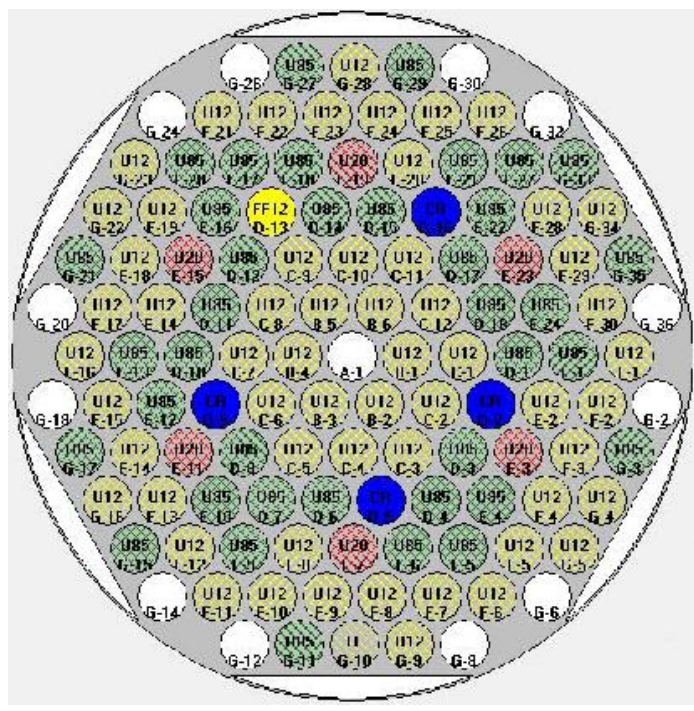

Gambar 2. Konfigurasi teras optimal (5)

Kemudian dengan cara yang serupa reaktivitas padam diperoleh sebesar $\$ 9,467$ respons subkritis, atau senilai $\$-9,467$. Berdasarkan kedua hasil ini karakteristik reaktivitas konfigurasi teras nampak cukup meyakinkan dengan control rod worth sebesar \$14,930. Namun untuk lebih meyakinkan, dimana kondisi kegagal-an jatuh salah satu batang kendali juga harus memberikan respons subkritis, maka perlu diperiksa juga reaktivitas kemungkinan setiap batang kendali gagal jatuh. Dari hasil simulasi dengan MCNP didapatkan hasil seperti ditunjukkan pada Tabel 1. Adapun ilustrasi kondisinya ditunjukkan pada Gambar 3. Dari gambar dapat disimpulkan bahwa kondisi one stuck rod criteria dipenuhi pada shim D13. 
Tabel 1. Reaktivitas pada kondisi satu batang kendali tersangkut

\begin{tabular}{cccc}
\hline SHIM & KEFF & \multicolumn{2}{c}{ REAKTIVITAS } \\
\cline { 3 - 4 } TERSANGKUT & & $\mathrm{dk} / \mathrm{k}$ & $\$$ \\
\hline D2 & 0.961 & -0.041 & -5.706 \\
D5 & 0.960 & -0.041 & -5.734 \\
D9 & 0.963 & -0.038 & -5.336 \\
D13 (FFCR) & 0.966 & -0.035 & -4.926 \\
D16 & 0.956 & -0.046 & -6.453 \\
\hline
\end{tabular}

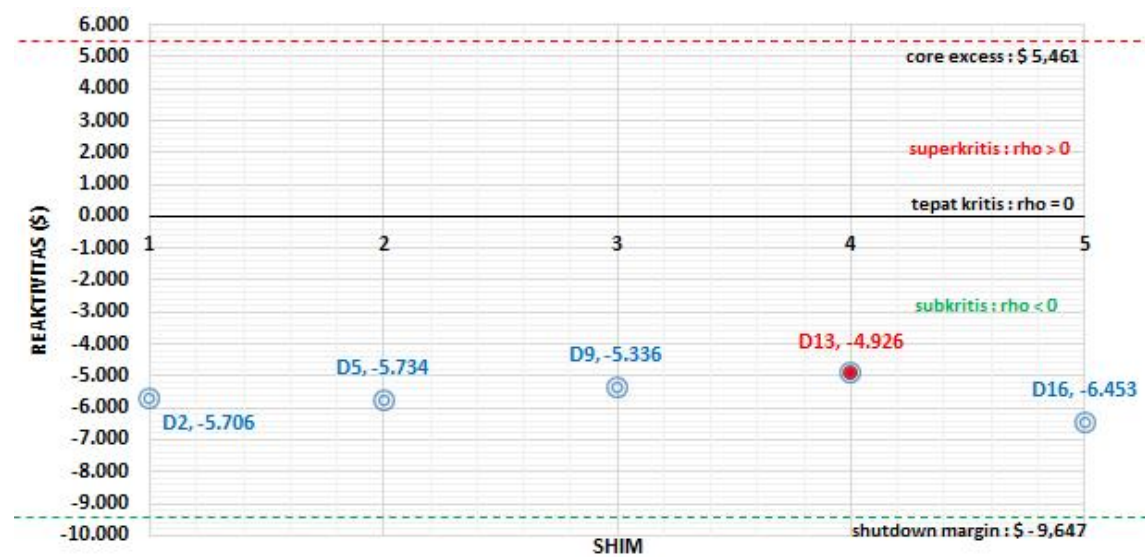

Gambar 3. Grafik karakteristik reaktivitas

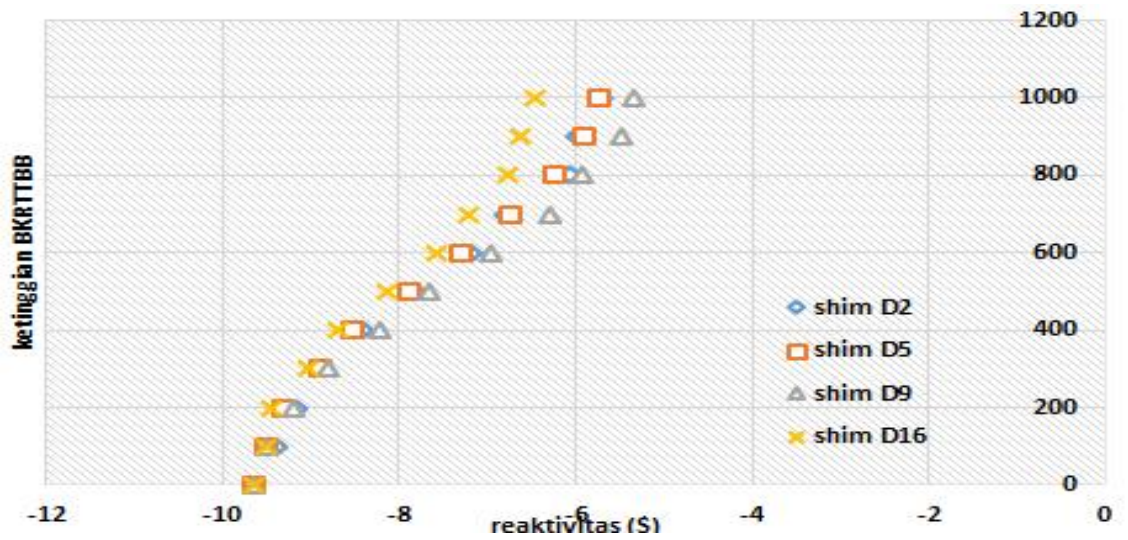

Gambar 4. Karakteristik pergesaran reaktivitas apabila salah satu BKRTTBB dinaikkan dari kondisi awal seluruh batang kendali di bawah

Untuk melihat kinerja keempat BKRTTBB ketika dinaikturunkan pada kondisi operasi di dalam teras dapat ditunjukkan pula oleh beberapa grafik pada Gambar 4, Gambar 5 dan Gambar 6. Gambar 4 menunjukkan karakteristik re- aktivitas apabila salah satu BKRTTBB dinaikkan dari kondisi awal seluruh batang kendali berada dibawah. Dari keempat BKRTTBB, BKRTTBB pada posisi shim D9 memberikan pergeseran reaktivitas yang lebih besar daripada ketiga lainnya. 


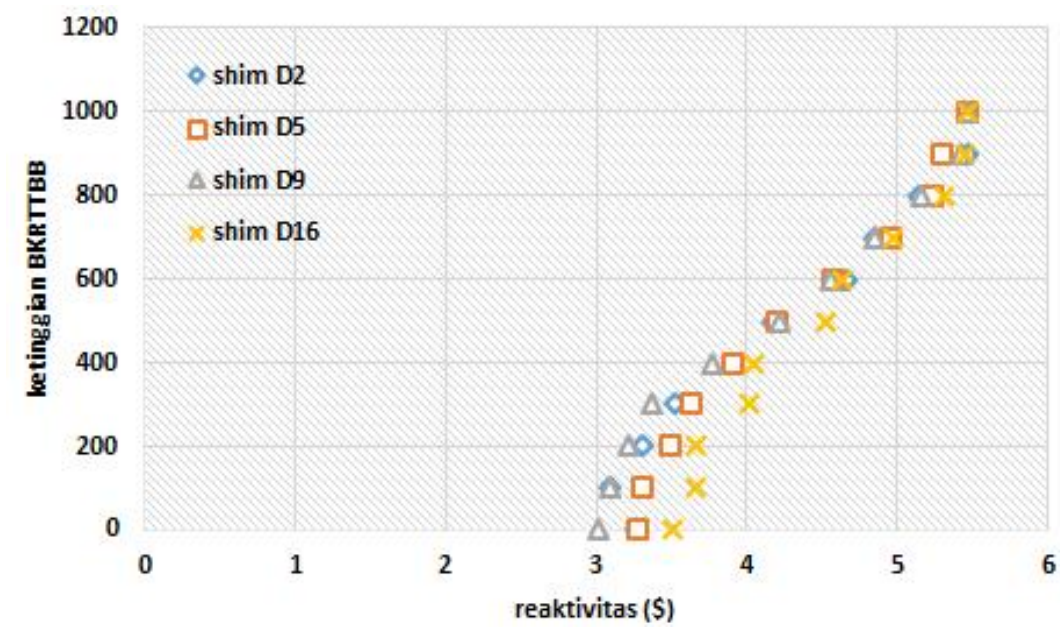

Gambar 5. Karakteristik pergesaran reaktivitas apabila salah satu BKRTTBB diturunkan dari kondisi awal seluruh batang kendali di atas

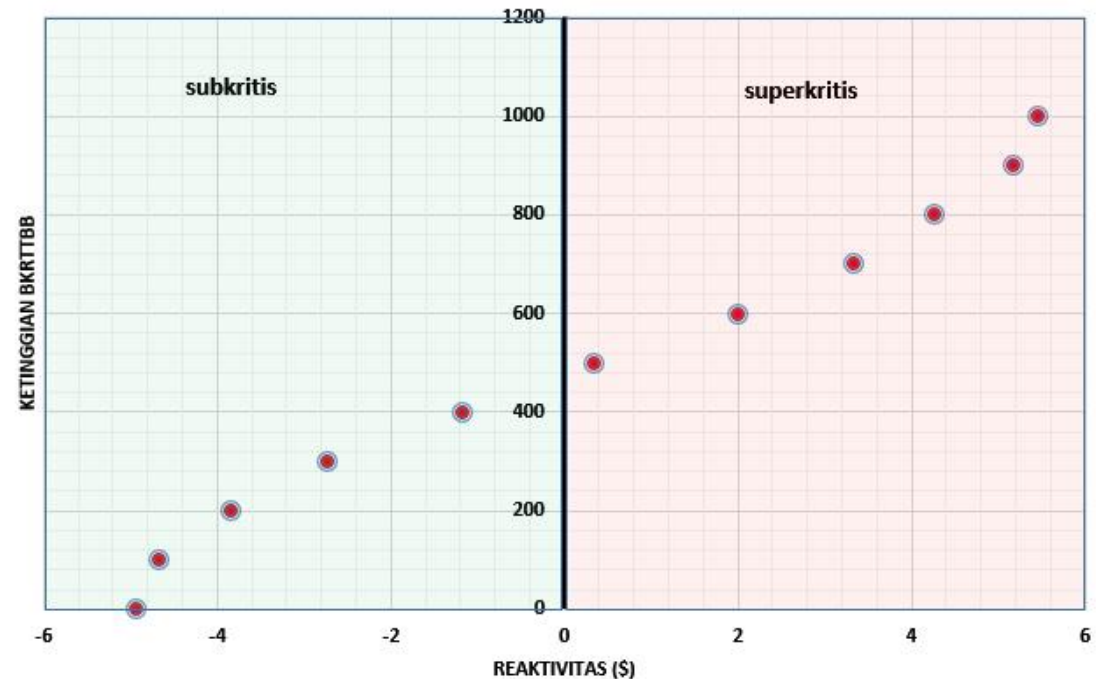

Gambar 6. Karakteristik pergesaran reaktivitas apabila seluruh BKRTTBB diturunkan dari kondisi awal seluruh batang kendali maksimum

Sebaliknya BKRTTBB pada posisi shim D16 memberikan pergeseran reaktivitas yang paling kecil.

Gambar 5 menunjukkan karakteristik reaktivitas teras apabila salah satu BKRTTBB diturunkan dari kondisi awal seluruh batang kendali berada pada posisi maksimum. Serupa dengan kesimpulan pada Gambar 4, BKRTTBB pada posisi shim D9 memberikan respons pergeseran re-aktivitas yang paling besar dan shim D16 memberikan respons pergeseran reaktivitas yang paling kecil. Gambar 6 menunjukkan karakteristik pergeseran reaktivitas apabila seluruh BKRTTBB diturunkan bersamaan dari kondisi awal seluruh batang kendali berada pada posisi maksimum. Dari gambar tersebut dapat disimpulkan bahwa keempat BKRTTBB memiliki kemampuan daya serap neutron yang baik. Dimana ketika seluruh BKRTTBB diturunkan reaktor secara signifikan mengalami penurunan reaktivitas 
Kajian Keselamatan Pengoperasian Reaktor Triga 2000

Bandung Dengan Menggunakan Batang Kendali Reaktor

Triga 2000 Tanpa Bahan Bakar (BKRTTBB) (Prasetyo)

sampai dengan tercapai kondisi subkritis pada $\$-4,926$.

Dari hasil kajian neutronik pada kondisi seluruh batang kendali dinaikkan maksimum adalah didapatkannya faktor puncak daya aksial sebesar 1,21 dan faktor puncak daya radial sebesar 2,02.

Dari Gambar 7 dan Gambar 8 dapat disimpulkan bahwa untuk setiap suhu masukan dan kenaikan daya maka suhu terpanas pada subbuluh tidak ada yang melebihi suhu jenuh air $\left(112^{\circ} \mathrm{C}\right)$ sehingga air pendingin tidak mengalami pendidihan apabila reaktor dioperasikan sampai dengan $1000 \mathrm{~kW}$ dengan suhu masukan $42^{\circ} \mathrm{C}$.
Kemudian pada kondisi khusus dimana suhu air masukan mendekati $49^{\circ} \mathrm{C}$, sebelum sinyal SCRAM terpicu, suhu terpanas air pendingin masih berada pada nilai $\quad 94,11^{\circ} \mathrm{C} \quad$ (STAT) dan $88,64^{\circ} \mathrm{C}$ (STATMOD).

Berdasarkan kedua kajian diatas maka, secara teoritik kegiatan modifikasi batang kendali FFCR menjadi BKRTTBB dengan konfigurasi 1 buah FFCR, 4 buah BKRTTBB, dan 102 elemen bakar standar masih memenuhi persyaratan keselamatan neutronik maupun termalhidrolik apabila reaktor dioperasikan pada daya $1000 \mathrm{~kW}$.

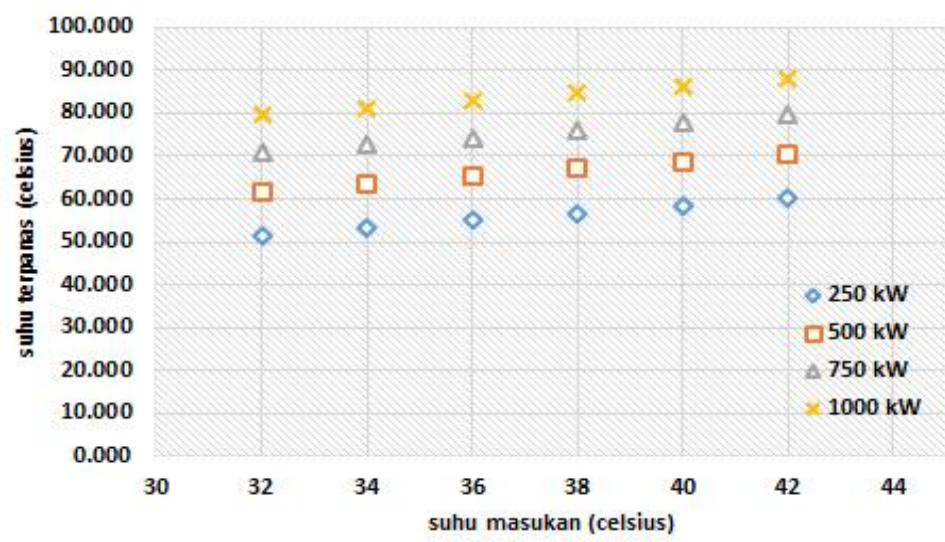

Gambar 7. Variasi suhu terpanas pada setiap tingkatan daya operasi dengan menggunakan STAT

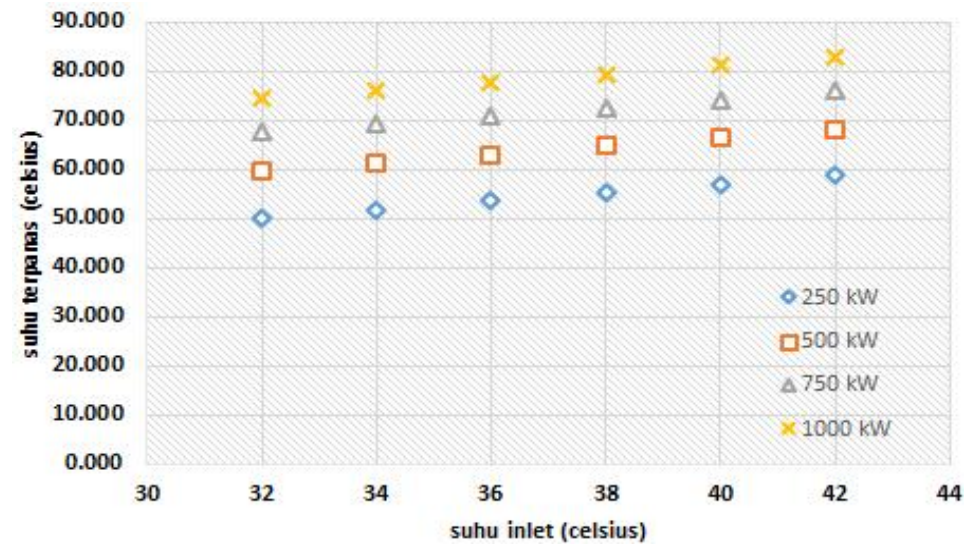

Gambar 8. Variasi suhu terpanas pada setiap tingkatan daya operasi dengan menggunakan STATMOD 


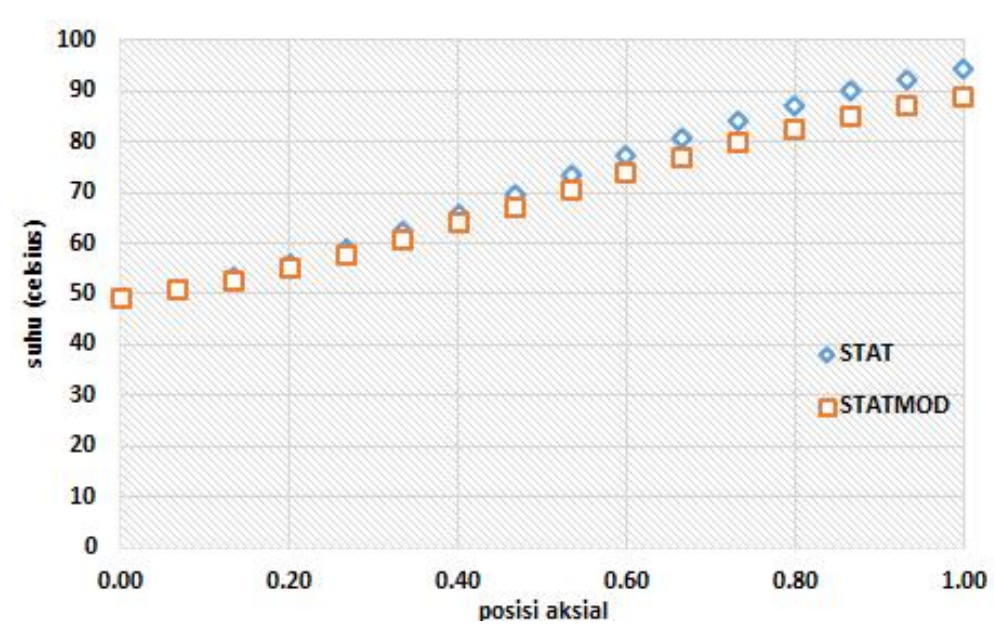

Gambar 9. Perbandingan distribusi suhu pada subbuluh apabila diberi suhu masukan $49^{\circ} \mathrm{C}$

\section{KESIMPULAN}

Hasil simulasi dengan menggunakan MCNP diperoleh bahwa konfigurasi teras optimal memiliki karakteristik reaktivitas padam $\$-9,467$ dan reaktivitas teras lebih $\$ 5,463$. Kemudian semua kondisi one stuck rod masih memenuhi persyaratan subkritis dimana tidak terdapat reaktivitas yang melampaui \$-0,5.

Hasil pengkajian termalhidrolik pada kondisi operasi pada daya 1000 kW juga cukup meyakinkan dimana untuk setiap kenaikan suhu masukan air pendingin sampai dengan $42{ }^{\circ} \mathrm{C}$, suhu air terpanas pada subbuluh masih berada dibawah suhu jenuh air $\left(112^{\circ} \mathrm{C}\right)$. Pada suhu masukan 42 ${ }^{\circ} \mathrm{C}$ di daya $1000 \mathrm{~kW}$, suhu terpanas pada subbuluh sebesar $87,98{ }^{\circ} \mathrm{C}$ (STAT) dan $82,75^{\circ} \mathrm{C}$ (STATMOD).

Kemudian dengan mensimulasikan kondisi mendekati LOFA dimana suhu air masukan mendekati $49{ }^{\circ} \mathrm{C}$ sama dengan suhu tertinggi air keluar menuju penukar kalor sebelum reaktor SCRAM, suhu terpanas $94,12^{\circ} \mathrm{C}$ dan $88,64{ }^{\circ} \mathrm{C}$.

Dari serangkaian hasil diatas maka dapat disimpulkan reaktor beroperasi dengan 4 buah BKRTTBB pada teras paling reaktif masih aman dan selamat.

\section{UCAPAN TERIMA KASIH}

Ucapan terimakasih ditujukan kepada seluruh personil PTBBN yang telah membantu PSTNT dalam membuat dan merakit BKRTTBB untuk dapat digunakan pada teras TRIGA 2000. Kemudian kepada Subbagian Perlengkapan yang telah banyak membantu dalam pengadaan sarana dan prasarana pendukung sehingga kegiatan modifikasi batang kendali dapat terlaksana dengan lancar.

Ucapan terimakasih kepada ibu Rosalina Fiantini yang telah meluangkan waktunya dalam membimbing personil bidang Reaktor untuk dapat menggunakan program komputasi STAT dan STATMOD.

Ucapan terimakasih setinggi-tingginya kepada seluruh rekan bidang reaktor yang telah bahu-membahu bekerja sama sehingga seluruh rangkaian kegiatan modifikasi batang kendali terlaksana dengan baik, aman, dan selamat. 


\section{DAFTAR PUSTAKA}

1. Abdul Rojak, Ahmad Paid. Perancangan elemen kendali tanpa fuel follower Reaktor TRIGA-2000 Bandung. Prosiding Seminar Pengelolaan Perangkat Nuklir, PTBBN-Serpong, 25 September 2013. hlm 8-16

2. Efrizon Umar. Prediction of mass flow rate and pressure drop in the coolant channel of the TRIGA 2000 reactor core. Atom Indonesia. Jakarta 2001: 67-84.

3. Efrizon Umar, Kamajaya K, Tandian NP, Hardianto T and Suwono A. An experimental study of natural convection in the hottest channel of TRIGA $2000 \mathrm{~kW}$. Pacific Basin Nuclear Conference, Australian Nuclear Association 2006.

4. Efrizon Umar. Studi termohidrolik pada reaktor nuklir-penelitian berbahan bakar silinder. Disertasi Program Doktor, Institut Teknologi Bandung. Bandung 2007.

5. Rosalina Fiantini, Efrizon Umar and D. Biksono. Thermal hydraulics study in the original design of TRIGA 2000 reactor. Proceedings of 8th International Topical Meeting on Nuclear Thermal Hydraulics, Operation and Safety (NUTHOS-8). Shanghai, China 2010.

6. Rosalini Fiantini and Efrizon Umar. Fluid flow characteristics simulation on the original TRIGA 2000 reactor core design using computational fluid dynamics code. The 2nd International Conference on Advances in Nuclear Science and Engineering, AIP Publication, Volume 1244. Melville, New York 2010.
7. Rosalini Fiantini, Nanda Nagara and Efrizon Umar. TRIGA 2000 reactor thermal hydraulics performance for $1 \mathrm{MW}$ power condition. Proceedings of International Conference on Cooling and Heating Technologies, Bandung 2010.

8. Efrizon Umar and Ketut Kamajaya. Redesign construction and operation characteristics of the primary cooling system of TRIGA 2000 reactor. Pacific Basin Nuclear Conference, Australian Nuclear Association 2006.

9. Efrizon Umar and Rosalini Fiantini. Modification of the core cooling system of TRIGA 2000 reactor. The 2 nd International Conference on Advances in Nuclear Science and Engineering, AIP Publication, Volume 1244, Melville, New York 2010.

10. Efrizon Umar, Kamajaya K, Suwono A, Tandian NP, Hardianto T. An experimental study of natural convection in the hottest channel of TRIGA $2000 \mathrm{~kW}$ reactor. Indonesian Journal of Nuclear Science and Technology 2005;6(1).

11.Prasetyo Basuki, P. Ilham Yazid, Zaki Suud. Desain neutronika elemen bakar tipe pelat pada teras TRIGA 2000 Bandung. Jurnal Sains dan Teknologi Nuklir Indonesia 2014; 15(2):69-80.

12.Luka Snoj, Matjaz Ravnik. Power peakings in mixed TRIGA cores. Proceedings of The International Conference Nuclear Energy for New Europe 2006. 
Jurnal Sains dan Teknologi Nuklir Indonesia

Indonesian Journal of Nuclear Science and Technology

Vol. 16, No 2, Agustus 2015; 93-104

ISSN 1411 - 3481 